\title{
HETEROTOPIA PEDAGÓGICA COMO LUGAR DE APARIÇÃO DAS SINGULARIDADES SURDAS NA EDUCAÇÃO
}

PEDAGOGICAL HETEROTOPIA AS WAYS TO SHOW THE PARTICULARITIES OF THE DEAF PERSONS IN EDUCATION

\author{
HETEROTOPIA PEDAGÓGICA COMO ESPACIO DE APARICIÓN DE LAS \\ SINGULARIDADES SURDAS EN LA EDUCACIÓN
}

Júlia Caroline de Araújo Almeida1 ${ }^{\text {; Vanessa Regina de Oliveira Martins }}{ }^{2}$

\begin{abstract}
RESUMO
Introdução: A partir do conceito de heterotopia cunhado por Michel Foucault e pela configuração de novos campos de saber na educação de pessoas surdas, com a emergência da perspectiva cultural, o presente artigo objetiva analisar práticas pedagógicas de professoras bilíngues atuantes em salas multisseriadas que tem a Libras (Língua Brasileira de Sinais) como língua de instrução, em escolas inclusivas, localizadas em dois municípios do estado de São Paulo. Justifica-se a pesquisa pelas novas configurações de perspectivas educacionais bilíngues para surdos, e ainda, pelas críticas dirigidas pelos surdos à proposta inclusiva, quando não se atenta às especificidades linguísticas e culturais desses sujeitos. Método: Tratou-se de uma pesquisa qualitativa com propostas investigativas do cotidiano escolar. Optamos pela descrição e análise de uma cena de uma das salas multisseriadas bilíngue inclusiva de surdos investigada. Resultados: As salas bilíngues mostraramse como espaço de resistência surda a partir da ação militante de educadores bilíngues. Conclusão: 0 artigo, portanto, pretende contribuir com educadores que também atuam com alunos surdos, resistem constantemente e buscam ressignificar suas práticas considerando sempre as singularidades de seus alunos no processo educativo.
\end{abstract}

PALAVRAS-CHAVE: Educação de surdos. Heterotopia. Instrução em Libras.

\section{ABSTRACT}

Introduction: from the concept of different spaces (heterotopy) invented by Michel Foucault and the configuration of new fields of knowledge in deaf education, with the emergence of cultural perspective, this article aims to analyze pedagogical practices of bilingual teachers who work in different series in Libras (Brazilian sign language) as the language of instruction, in inclusive schools located in two municipalities of the state of São Paulo. The research is justified by the new configurations of bilingual educational perspectives for the deaf and also by the criticisms addressed by the deaf to the inclusive proposal when one does not pay attention to the linguistic and cultural specificities of these subjects. Method: it was a qualitative research with proposals of investigation of the routine of a classroom with different series of the school. We opted for the description and analysis of a scene from one of the bilingual inclusive classrooms of deaf people investigated. Results: bilingual rooms were shown as a space of resistance of the deaf through the militant action of bilingual educators. Conclusion: The article therefore intends to contribute with educators who also work with deaf students, constantly resist and seek new practices always considering the singularities of their students in the educational process.

\footnotetext{
${ }^{1}$ Mestre em Educação Especial - Universidade Federal de São Carlos (UFSCar/PPGEEs) - São Carlos, SP - Brasil. Professora bilíngue de surdos - Rede Municipal de São Carlos - São Carlos, SP - Brasil. E-mail: almeida.jcaa@gmail.com

${ }^{2}$ Doutora em Educação - Universidade Estadual de Campinas (UNICAMP). Professora e pesquisadora Universidade Federal de São Carlos (UFSCar) - São Carlos, SP - Brasil. Docente no Programa de Pós-graduação em Educação Especial (PPGEEs/UFSCar) - São Carlos, SP - Brasil. E-mail: vanymartins@hotmail.com Submetido em: 02/04/2018 - Aceito em: 08/01/2019
}

(C) ETD- Educação Temática Digital Campinas, SP $\quad$ v.21 $\quad$ n.3 $\quad$ p.695-717 jul./set. 2019


KEYWORDS: Deaf education. Different spaces (heterotopia). Education in Libras.

\section{RESUMEN}

Introducción: A partir del concepto de heterotopía acuñado por Michel Foucault y por la configuración de nuevos campos de saber en la educación de personas sordas, con la emergencia de la perspectiva cultural, el presente artículo objetiva analizar prácticas pedagógicas de profesoras bilingües actuantes en salas multiserias que tienen la Libras (Lengua Brasileña de Señales) como lengua de instrucción, en escuelas inclusivas, ubicadas en dos municipios del estado de São Paulo. Se justifica la investigación por las nuevas configuraciones de perspectivas educativas bilingües para sordos, y aún, por las críticas dirigidas por los sordos a la propuesta inclusiva, cuando no se atenta a las especificidades lingüísticas y culturales de esos sujetos. Método: Se trata de una investigación cualitativa con propuestas investigativas del cotidiano escolar. Optamos por la descripción y análisis de una escena de una de las salas multiseriales bilingüe inclusiva de sordos investigada. Resultados: Las salas bilingües se mostraron como espacio de resistencia sorda a partir de la acción militante de educadores bilingües. Conclusión: El artículo, por lo tanto, pretende contribuir con educadores que también actúan con alumnos sordos, resisten constantemente y buscan rehacer sus prácticas considerando siempre las singularidades de sus alumnos en el proceso educativo.

PALABRAS CLAVE: Educación de sordos. Heterotopia. Instrucción en Libras.

\section{INTRODUÇÃO}

Dialogar entre práticas de ensino de surdos, resistências a modelos impostos a partir de uma única fôrma, bem como observar a irrupção de práticas voltadas à manutenção das diferenças ou aparição de singularidades é a proposta central desta escrita. Como os estudos na perspectiva foucaultiana apontam para as tensões de verdades formuladas na constante refacção delas em direção à manutenção da diferença, o objetivo principal deste trabalho foi o de analisar, a partir do conceito de heterotopia, cunhado por Foucault (2013), as práticas pedagógicas de duas professoras bilíngues atuantes em salas multisseriadas ${ }^{3}$, com alunos surdos inseridos em escolas com uma Proposta Educacional Inclusiva Bilíngue, localizadas em dois municípios do interior do estado de São Paulo. Importante destacar que o conceito de heterotopia, tal qual proposto, descreve lugares, espaços e ações que funcionam em condições não hegemônicas, como espaços que produzem a abertura de outros espaços, novos encontros, potencializando a produção criativa e inventiva. Por essa razão, atrelado ao conceito de heterotopia, utilizamos outro conceito do mesmo filósofo, a saber, a resistência ou a contra-conduta aos saberes impostos como verdades absolutas. Com as análises realizadas observa-se que as práticas das professoras bilíngues participantes deste estudo caracterizam-se como práticas pedagógicas heterotópicas devido às resistências que diariamente precisam impor ao sistema hegemônico que as regem (sistema inclusivo voltado

\footnotetext{
${ }^{3} \mathrm{~A}$ sala multisseriada para alunos surdos é confundida com as antigas salas de recursos que atendiam alunos público-alvo da educação especial no contraturno das escolas regulares e destinavam maior atenção às atividades de vida diária (AVD) e/ou à revisão dos conteúdos estudados na sala regular, atuando mais como um reforço escolar. Há atualmente as salas multisseriadas que atendem alunos do campo (zona rural). No entanto, ressalta-se que, neste artigo, o termo multisseriada caracteriza as salas regulares com uma proposta de ensino bilíngue, que estão inseridas em escolas comuns (escolas-polos inclusivas bilíngues) e atendem alunos surdos e ouvintes (se for a opção da família, como é o caso de crianças ouvintes filhas de pais surdos) do 10 ao 5o ano do ensino fundamental. No item 2.1 aprofundaremos a caracterização desta sala e adensaremos as discussões sobre este espaço.
}

(C) ETD- Educação Temática Digital Campinas, SP $\quad$ v.21 $\quad$ n.3 $\quad$ p.695-717 jul./set. 2019


ao público ouvinte). É interessante apontar, sobre a observação cotidiana na pesquisa, que a ação da resistência não é algo sempre presente, sendo, portanto, focos que emergem em pequenos instantes e que muitas vezes parecem insignificantes, no entanto, é ali (no filete de tempo/espaço) que vemos aparecer fluxos de diferenças que são, por vezes, sufocadas ou ainda, silenciadas na engrenagem escolar.

Por essa razão, objetivou-se também, compreender como os conceitos foucaultianos, em especial, o de resistência e o de diferença, dialogam com o campo da surdez, especificamente da educação de surdos. Com isso aprofundamos as análises de possibilidades de ações resistivas que se dão no cotidiano e no contexto escolar. Deste modo, destaca-se a ação de trazer ao diálogo atos concernentes ao interior da sala de aula, ou seja, um contexto micro-político, ou ainda, como denominado por Gallo (2007), práticas de uma educação menor - entendendo-a como espaço de produção e aparição das singularidades e dos encontros dos sujeitos com fluxos de aprendizagens e de saberes que por vezes não são tomadas como produções positivas ou hegemônicas pela escola. Segundo o autor, "uma das características mais fortes e importantes da educação menor é o seu potencial de resistência" (GALLO, 2007, p. 38). Portanto, pretende-se que este artigo promova reflexões, aos leitores, sobre as resistências surdas na escola por meio do espaço que a língua de sinais ocupa em salas multisseriadas, sendo um material importante para professores bilíngues e outros professores que também atuam com alunos surdos em um cenário escolar inclusivo. Assim, mesmo que em contextos diferentes e com alunos com especificidades diferentes, o presente trabalho, pode ser também uma contribuição para professores que almejam transformar a sua ação pedagógica cotidiana em atos micro-revolucionários.

\section{EDUCAÇÃO DE SURDOS E OS DESAFIOS DOCENTES ATUAIS OLHADOS PELAS FILOSOFIAS DA DIFERENÇA}

As filosofias da diferença são produzidas a partir de vários autores que abordam como eixo central de suas discussões a necessidade de livrar-se de conceitos universais e modos unívocos de ver o mundo, os sujeitos e as práticas sociais. Para Foucault (2014), como também para Nietzsche, a verdade é uma construção histórica. Não existe uma verdade universal. A filosofia é uma, dentre outras formas de se pensar os dilemas humanos e, conforme Deleuze e Guattari (1992) é responsável pela criação de conceitos - os quais são utilizados como ferramentas para a reflexão e construção de inúmeras verdades e produções teóricas. Por isso, na perspectiva aqui assumida não há conhecimentos prontos e acabados. A verdade é uma invenção social e efeito das relações de poder e estas relações, por sua vez, geram inúmeros saberes. Portanto, saber e poder estão intimamente relacionados na visão foucaultiana. Para Gallo (2016a) a reflexão sobre a diferença foi inaugurada pelo pensamento nietzchiniano e ancorada por outros filósofos (como Michel Foucault, Gilles Deleuze, Félix

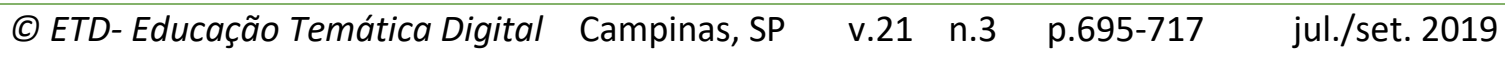


inventiva e a aparição de saberes menos dominantes, mais criativos, ou como nomeado por Foucault (2014), saberes locais, ou saberes das pessoas.

Sendo assim, podemos pensar no processo educativo como importante na construção dos sujeitos ${ }^{4}$ entendendo-o como um meio de cuidado de si ou refacção de si mesmo, como um espaço de reconstrução e ressignificações. O professor pode exercer nas micro-relações diárias, ações que burlam a formatação e caminham no desejo do aluno. Em muitas salas de aulas, no interior do espaço escolar, ações menores e criativas ensaiam uma educação singular para além da perspectiva normativa, direcionando-a ao desejo dos alunos, que pode ser outro, para além do prescrito pelo programa/currículo.

Neste artigo, que alinha a educação às filosofias da diferença, trabalhamos mais fortemente com obras e produções reflexivas produzidas por Michel Foucault, Gilles Deleuze e estudiosos desses autores. Especificamente, ao pensar na educação de surdos como produtora de diferenças pelo fato de trazer uma língua gestuovisual, diferente da língua oficial de instrução escolar: o português. Utilizamos autores que se filiam a essa mesma matriz de saber e também têm problematizado a diferença surda na escola, tais como: Lopes (2011), Martins (2013) e Souza (2010). Usamos também o conceito de matriz de experiência, a qual funda campos de saber, como espaço de negociação de sentidos por meio de saberes produtores de verdades que se produzem pela experiência sendo forjada em três eixos: 1) da constituição de um saber; 2) da normatividade dos comportamentos pela ação do poder, 2) do modo de produção de subjetividade, na relação ética. (FOUCAULT, 2010).

Embora os dois filósofos franceses mencionados não tenham escrito especificamente para o campo da educação, suas obras nos ajudam a pensar esse campo de saber e as problematizações dele derivado. Deleuze, por exemplo, nas obras "Proust e os signos" e "Diferença e repetição" nos dá indícios de que a teoria do ensino-aprendizagem (com hífen), muito difundida pela Pedagogia do século $X X$, não faz sentido à filosofia da diferença. Isso porque, essa teoria concebe que só há aprendizagem quando há o ensino sistematizado, controlado, metodologizado, ou seja, que a aprendizagem está colada diretamente e exclusivamente ao ensino. Ou ainda: alguém só aprende aquilo que é ensinado ou da maneira como é ensinado. No entanto a crítica deleuziana se refere pelo não controle da aprendizagem e a forma singular como ela se dá. Não se trata de desqualificar o trabalho

\footnotetext{
${ }^{4}$ Vale ressaltar que Foucault compreende o sujeito diferente do cartesianismo moderno, alterando o sentido da palavra sujeito, até então utilizado. Para Foucault, o sujeito é uma ficção, um produto das normas e pode se refazer por meio das ações que exerce sobre si, portanto, não existe o a priori do sujeito, nem uma essência que o determine de modo único, já que ele é feito e efeito das relações. Foucault é bastante contundente ao afirmar que é contrário à ideia de se fazer previamente uma teoria do sujeito, uma teoria a priori do sujeito, como se fosse possível supor a existência de uma essência humana que tivesse sido mascarada, alienada ou aprisionada em mecanismos de repressão a partir de processos históricos, econômicos e sociais. $\mathrm{O}$ autor postula que o sujeito é histórico, mas produzido na sua própria história e pela história que o permeia através do que denominou de uma "história da verdade" (MURAD, 2010, p. 1).
}

(C) ETD- Educação Temática Digital Campinas, SP $\quad$ v.21 n.3 $\quad$ p.695-717 jul./set. 2019 
do professor ou de alguém que ensina, pelo contrário, sua mediação é importante, mas o aprendiz poderá fazer sentido para si de elementos que se quer o educador imaginava que seriam frutíferos. Deste modo, a aprendizagem parece estar mais relacionada ao encontro do aprendiz com o signo (elementos de sentido exposto pelo professor ou não) que está sendo apreendido. (GALLO; ASPIS, 2011).

Não significa também que o trabalho do professor deva ser menosprezado e o processo deva ser centrado apenas nos alunos. Pelo contrário, Deleuze, nos chama a atenção para o fato de que por mais frágil que seja a atuação do professor, é possível criar dela, ou a partir de sua presença, um acontecimento. Se o professor se ocupar do processo do aprender e não apenas de seu resultado (ou o que o aluno aprendeu daquilo que foi ensinado), realizando seu trabalho de ensino de maneira conjunta ao caminhar e às descobertas do aluno, já estará fazendo o necessário e ainda abrindo-se às experiências e desejos que decorrem do percurso do ato (corpóreo) de aprender. Certamente efeitos importantes poderão ser alcançados desta prática. O que não pode ocorrer é se deixar levar pela impotência e paralisia no processo. É possível refletir sobre esses atos cotidianos que se dão no interior da sala de aula a partir da obra "Kafka, por uma literatura menor" de Deleuze e Guattari (1977). Neste livro, os filósofos criaram os conceitos de literatura maior e literatura menor. A literatura maior é a que se faz no âmbito da língua estabelecida e a menor é aquela produzida pela minoria, que não segue a norma padrão e irrompem criações, memorizações, na lógica da língua maior (GALLO; ASPIS, 2011).

Se pensarmos nestes conceitos de maior/menor projetando-os ao campo da educação, conforme produção de Gallo (2002), teremos também uma educação maior quando se faz uma política pública educacional que se estabelece por todo o país, que produz uma norma, um programa que sistematiza de um único modo o fazer docente. Já uma educação menor pode ser feita no trabalho efetivo que o professor realiza no interior de sua sala de aula, sozinho com seus alunos, distante dos olhares dos órgãos reguladores da educação e que para o aluno, é esse ato que trará para si sentidos múltiplos.

\begin{abstract}
A educação maior é aquela dos planos decenais e das políticas públicas de educação, dos parâmetros e das diretrizes, aquela da constituição e da LDB, pensada e produzida pelas cabeças bem-pensantes a serviço do poder. A educação maior é aquela instituída e que quer instituir-se, fazer-se presente, fazer-se acontecer. A educação maior é aquela dos grandes mapas e projetos. Uma educação menor é um ato de revolta e de resistência. Revolta contra os fluxos instituídos, resistência às políticas impostas; sala de aula como trincheira, como a toca do rato, o buraco do cão. Sala de aula como espaço a partir do qual traçamos nossas estratégias, estabelecemos nossa militância, produzindo um presente e um futuro aquém ou para além de qualquer política educacional. Uma educação menor é um ato de singularização e de militância (GALLO, 2002, p.173).
\end{abstract}

Deste modo, o trabalho solitário de um professor em sua sala de aula também tem uma significação política, assim como a literatura menor de Kafka, porque o professor não

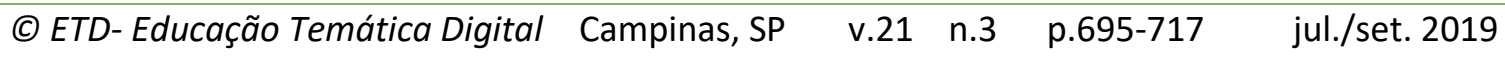


fala em nome próprio, mas em nome de um coletivo. É o professor que diariamente precisa encontrar linhas de fuga para atuar em contextos onde as leis e diretrizes educacionais pensadas, formuladas e impostas pelos regimes de controle, não atendem as demandas do cotidiano escolar, sendo muitas vezes desconexas à realidade escolar brasileira.

\footnotetext{
Se há uma literatura menor, por que não pensarmos numa educação menor? Para aquém e para além de uma educação maior, aquela das políticas, dos ministérios e secretarias, dos gabinetes, há também uma educação menor, da sala de aula, do cotidiano de professores e alunos. É essa educação menor que nos permite sermos revolucionários, na medida em que alguma revolução ainda faz sentido na educação em nossos dias. A educação menor constitui-se, assim, num empreendimento de militância (GALLO, 2002, p. 169).
}

Traçando a reflexão da ação docente e considerando especificamente as políticas que regem a inclusão dos alunos com deficiência no sistema regular de ensino, a ação do professor, bem como, de todos os educadores que colaboram com o processo educacional (diretor, coordenador, agentes educacionais, funcionários do setor da limpeza; administrativos; merendeiras...) é o de atuar de modo a produzir singularizações das experiências e das diferenças em espaços escolares que se propõem inclusivos. Isso por determinação das secretarias de educação e do ministério da educação, porém, muitas vezes encontram no cotidiano escolar dificuldades diversas: despreparo profissional - reflexo de lacunas durante o processo de formação docente e inexistência de formação continuada efetiva; ausência de materiais e estrutura física adequada; elevado número de alunos em cada sala de aula, dificultando o atendimento mais individualizado aos alunos com necessidades de adequações curriculares, dentre outros problemas. No entanto, o discurso da inclusão nos documentos legais, por vezes, simula escolas que não existem de fato. Divulga-se em nome de uma ideologia, uma escola que se torna homogênea a partir da convivência entre os diferentes. Essa é a grande polêmica em torno da perspectiva inclusiva de modo geral: produzir um ensino para todos, podendo perder, assim, as singularidades de cada um. Podemos problematizar que toda a ação feita rumo à homogeneização tende a apagar as diferenças (LODI, 2013; MARTINS, 2016).

Se a inclusão é efeito do processo de exclusão altamente formulado na sociedade capitalista que opera em uma maquinaria eficiente, por meio da categorização e nomeação de qualquer forma de diferença, sempre haverá, desta maneira, a captura por um sistema normativo e voraz. Parece-nos que a surdez ainda é prescrita, classificada e, portanto, nomeada na educação pela inscrição, ou lógica, patológica. O reparo para o surdo e seu corpo se faz na mesmidade de oferta de um ensino por uma língua que biologicamente, pela condição de não-ouvinte, o surdo não pode ter acesso: a inclusão aqui opera verdadeiramente pela promoção da exclusão. Para mudanças, ou forças reativas, requer, assim, uma nova configuração discursiva e um novo saber que emirja nas relações educacionais, desdobrando em novas práticas que fraturem as verdades postas e aparentemente eternizadas [...] (MARTINS, 2016, p. 719-720).

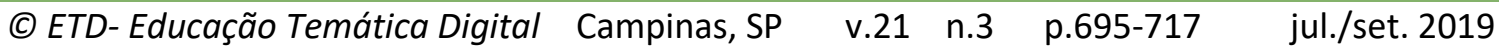


A inclusão dos surdos e as decisões sobre o melhor tipo de educação que lhes deve ser ofertado, sem a participação efetiva da comunidade surda, podem ser consideradas, alegoricamente, como uma réplica nos dias atuais do Congresso de Milão de 1880. Naquela ocasião, foi discutida a educação que os surdos deveriam receber, sem contar com a opinião deles.

\begin{abstract}
Nesse Congresso, que no momento da deliberação não contava com a participação nem com a opinião da minoria interessada - os surdos -, um grupo de ouvintes impôs a superioridade da língua oral sobre a língua de sinais e decretou que a primeira deveria constituir o único objetivo do ensino. A discussão foi extremamente agitada e por ampla maioria, o Congresso declarou que o método oral, na educação de surdos, deveria ser preferido em relação ao gestual, pois as palavras eram, para os ouvintes, indubitavelmente superiores aos gestos (SILVA, 2006, p. 26).
\end{abstract}

Além das indevidas adequações mínimas para a inclusão efetiva do aluno surdo, como por exemplo, apenas a inserção de um tradutor/ intérprete de Língua de Sinais, a realidade quase que generalizada das escolas brasileiras é do ensino da língua portuguesa sendo feita igual a alunos surdos e ouvintes - com as mesmas formas metodológicas. "Promove-se o discurso da inclusão, no entanto, o surdo se torna um incluso-excludente, está na sala de aula, mas sua língua é destituída de poder, de lugar, de funcionamento" (CARVALHO; MARTINS, 2016, p. 409).

Aliás, a essa proposição, podemos acrescentar os alunos indígenas ou oriundos de comunidades de imigrantes. A esses alunos também é oferecida a mesma aula, utilizando as mesmas estratégias, metodologia e avaliação de desempenho. Mesmo para alunos surdos usuários da língua de sinais e com a língua presente no contexto escolar - na maioria das vezes, apenas pela presença do intérprete de Libras/Língua Portuguesa - às duas línguas não são conferidas exercendo o mesmo status linguístico, tanto no processo educativo, quanto nos momentos de avaliações. E isso não ocorre apenas na disciplina de Língua Portuguesa (LP), mas perpassa todos os componentes curriculares, isso porque, a LP está presente em todos eles como língua de instrução escolar. O que quer dizer que os conteúdos são instruídos por meio dela. Dessa maneira ocorre que nas disciplinas de ciências, história e geografia, por exemplo, o aluno surdo não é avaliado pelo desempenho e aprendizagem dos conteúdos dessas disciplinas (sem levar em consideração a avaliação feita na Libras) e sim pelo seu aprendizado do português, uma vez que as avaliações dos mesmos se dão pela língua portuguesa. No momento da avaliação ele precisa demonstrar o que apreendeu dos conteúdos em uma segunda língua, aliás, língua que não the é natural e por essa razão não Ihe permite expressar-se livremente.

Como a escola só investe no desenvolvimento do dialeto de prestígio, ela acaba avaliando a competência do aluno bidialetal pela metade. Tudo que ele é capaz de fazer com a linguagem em seu próprio dialeto é desconsiderado, ignorado, deixado de fora da sala de aula. (MAHER, 2007, p. 70).

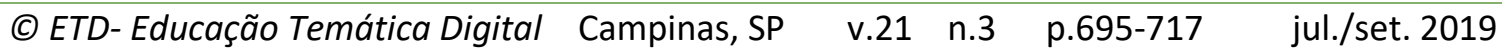


As discussões promovidas por Maher (2007) sobre o bilinguismo e o multilinguismo na sociedade, conferem importância para esse estudo. A autora aponta a essencialização de um bilinguismo inexistente, como se as habilidades tivessem que ser as mesmas na transição e uso das línguas pelo falante. Essa romantização do bilíngue ideal interfere nas práticas educacionais com alunos surdos. É necessário atentar-se para não se deixar cair na armadilha de exigir que o aluno surdo desenvolva habilidades iguais nas duas línguas e que consiga usálas sem que uma interfira na outra, ou seja, retomando a crença de um bilíngue perfeito (MAHER, 2007). Esse tema, da perspectiva bilíngue e das práticas de ensino e circulação da língua de sinais, é bastante relevante para nosso objetivo de reflexão, já que se buscou analisar as práticas de professoras bilíngues e a centralidade da língua de sinais nas salas onde a proposta básica é ter como língua de instrução a Libras. Ao produzir um ensino baseado na instrução pela Libras, propõe-se outros modos de realização e relação docente e do currículo escolar. Adotar a Libras como língua de empoderamento e de ensino é uma ação resistiva, que ativa a participação de surdos na escola, e que temos chamado aqui, baseado em Luz (2013), como a potencialização da aparição de vidas surdas singulares na escola inclusiva.

\section{EDUCAÇÃO DE SURDOS E A PROPOSTA BILÍNGUE EM SALAS MULTISSERIADAS DE SURDOS}

Pensando neste contexto de exclusão escolar - dentro dos discursos inclusivos - e em consonância com o que prevê o Decreto 5626/2005 (BRASIL, 2005), em 2003 - após a Lei de Libras (BRASIL, 2002) - foi implantado um Programa Educacional Inclusivo Bilíngue ${ }^{5} \mathrm{em}$ duas escolas municipais (uma de educação infantil e outra de ensino fundamental) em Piracicaba, uma cidade do interior do Estado de São Paulo. A implantação do programa emergiu no contexto de produção de saberes sócio-antropológicos, dentro de um status que pensa o bilinguismo e respeito à língua de sinais, fruto de estudos de um grupo de pesquisadores da área da surdez em parceria com a Prefeitura Municipal de Piracicaba; com o Fundo de Apoio à Pesquisa da Universidade Metodista de Piracicaba; do CNPq e da Fapesp ${ }^{6}$

O objetivo era preparar essas escolas para o atendimento de alunos surdos por meio de um programa de inclusão bilíngue. A incorporação da Libras, no espaço escolar, implicava enfrentar ainda desdobramentos metodológicos e o desenvolvimento de didáticas apropriadas para esses alunos (LACERDA; LODI, 2009, p. 19).

\footnotetext{
5 A expressão é apresentada em itálico para marcar que este é o título original escolhido pelas professoras/pesquisadoras responsáveis pelas pesquisas sobre a educação de surdos que culminaram na implantação do referido programa a esses alunos. O contexto e histórico de criação do programa constam em Lacerda; Santos; Lodi; Gurgel (2016), na obra "Escola e Diferença: caminhos para educação bilíngue de surdos" (LACERDA; SANTOS; MARTINS, 2016). A partir de agora usaremos apenas o termo "o Programa" para referenciálo.

${ }^{6}$ Descrição detalhada com os números dos processos das instituições de fomento em Lacerda; Santos; Lodi; Gurgel (2016, pp. 13 a 28).
}

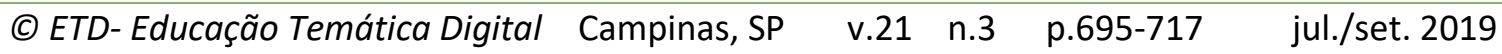


A Rede municipal de ensino da cidade em questão, por meio da Secretaria de Educação, indicou como condição para a implantação do programa que fosse garantida a inclusão dos alunos surdos em salas regulares de ensino e com adequação à restrição orçamentária do município. Logo, era preciso desenvolver uma proposta que incluísse as crianças surdas, contratando o mínimo possível de profissionais e utilizando o máximo possível de recursos já disponíveis na rede municipal de ensino (LACERDA, SANTOS, LODI, GURGEL, 2016).

Diversas ações foram então iniciadas, envolvendo capacitação dos profissionais da Rede Municipal e a contratação/capacitação de novos profissionais para desempenharem a função de instrutores surdos e de tradutores e intérpretes de LIBRAS (LACERDA, SANTOS, LODI, GURGEL, 2016, p. 21).

O Programa ocorreu de 2003 a 2007, junto à Rede Municipal de Piracicaba e neste período foi possível observar que as crianças surdas apresentaram avanços no que diz respeito à aquisição da Libras e desenvolvimento de linguagem, mas ainda precisava de um espaço mais intensivo e de modo natural para a aquisição em Libras na educação infantil e nos anos iniciais de ensino. Isso quando olhada as atividades escolares e criação de relações estreitas com os pares ouvintes que compartilhavam do ensino na mesma sala de aula, nos anos iniciais (LACERDA, SANTOS, LODI, GURGEL, 2016).

No entanto, apesar destes ganhos, o desenvolvimento das crianças ainda estava aquém do esperado e desejado pelas pesquisadoras, principalmente no que diz respeito à aprendizagem da Língua Portuguesa no Ensino Fundamental e, no caso das crianças da Educação Infantil, em sua fluência em LIBRAS (LACERDA, SANTOS, LODI, GURGEL, 2016, p. 21).

Todavia, com os avanços significativos apresentados a partir da implantação do programa educacional bilíngue citado acima, as pesquisadoras foram procuradas por representantes da Secretaria Municipal de Educação da cidade de Campinas a fim de que o mesmo programa fosse replicado em sua rede de ensino. Considerando as lacunas observadas pelas pesquisadoras após a implantação do programa em Piracicaba, conforme citamos anteriormente surgem em seguida, as escolas-polos bilíngues com outra configuração.

O Programa em sua nova configuração pretendia garantir para os anos iniciais (Educação Infantil e anos iniciais do Ensino Fundamental) que os alunos tivessem acesso aos conteúdos escolares por meio da sua língua matriz, ou seja, pela Libras, sendo estabelecida por meio de professores bilíngues. Para os anos finais do Ensino Fundamental e para o Ensino Médio, todo o processo educacional deveria ser realizado com a presença de profissionais tradutores/intérpretes de Libras/Língua Portuguesa (TILSP) em cada sala onde houvesse aluno surdo. Além disso, aos professores regentes das disciplinas nas salas de aulas regulares do 60 ao 9o anos e ensino médio, deveria ser oferecida uma formação em serviço a fim de que compreendessem a singularidade do seu aluno surdo; entendessem a diferença da

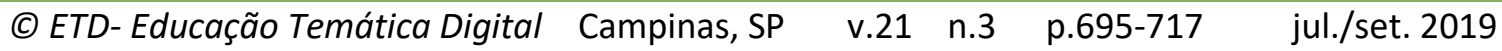


relação estabelecida pelo aluno surdo com a Língua Portuguesa escrita se comparado ao aluno ouvinte; compreendessem também a função do profissional TILSP e que a efetividade do trabalho se daria na medida em que ambos (professor e intérprete) atuassem em parceria (LACERDA, SANTOS, LODI, GURGEL, 2016). Outro adendo é o de que nos anos finais do ensino fundamental e ensino médio a aula de língua portuguesa se dava em espaço separado, entre surdos e ouvintes, com professores bilíngues para instruir este ensino na perspectiva de segunda língua.

Essa nova configuração do Programa foi implantada na Rede Municipal de Ensino da cidade de Campinas em 2008 e replicada posteriormente em outras redes de ensino de municípios situados no interior e no estado de São Paulo.

A principal alteração na proposta inicial foi a implementação das salas regulares de ensino onde todos os processos interacionais e de ensino e aprendizagem se dessem pela língua de sinais. Estas salas passaram a ser denominadas "salas LIBRAS língua de instrução" ou "salas multisseriadas bilíngues"7 (LACERDA, SANTOS, LODI, GURGEL, 2016, p. 21).

Desta forma, o Programa desde então apresenta a seguinte configuração: do 10 ao 50 ano (Ensino Fundamental I), os alunos surdos são agrupados em uma mesma sala (devido número reduzido de alunos surdos em cada ano) com professores bilíngues e a Língua de Instrução é a Libras, por isso a denominação Sala Multisseriada - Língua de Instrução Libras. No Ensino Fundamental II (6 ao 9ㅇ ano), os alunos são inseridos em salas de aulas com alunos ouvintes e contam com a presença de Intérprete educacional de Libras/Língua Portuguesa nas aulas de todas as disciplinas, exceto, como mencionado anteriormente, nas aulas de Língua Portuguesa, que são oferecidas por professor bilíngue em outro espaço, com uma metodologia de ensino diferenciada da que é utilizada com os ouvintes, isso porque, a Língua Portuguesa, para o aluno surdo é uma segunda língua. Esta configuração permite ao aluno surdo adquirir a Língua de Sinais (L1- primeira língua), desenvolvê-la através da relação com seus pares e aprender a Língua Portuguesa (L2 - segunda língua), na modalidade escrita (LACERDA; SANTOS; MARTINS, 2016).

Esta proposta, com nova configuração, mais especificamente, com o surgimento das salas LIBRAS língua de instrução, promoveu uma alteração à perspectiva inclusiva até então oferecida aos surdos, a qual não oferecia condições propiciais para que estes se desenvolvessem academicamente, de acordo com o esperado para sua faixa etária. Isto porque, embora tal proposta ocorra em escolas regulares inclusivas, agrupar todos os alunos

\footnotetext{
${ }^{7} \mathrm{O}$ principal pressuposto que fundamenta a criação destas salas é que é pela linguagem e na linguagem que o sujeito pode constituir-se e construir conhecimentos. E a linguagem, por sua vez, só se desenvolve quando existe a partilha de uma mesma língua (LODI; LACERDA, 2009). Desta forma, essas salas se configuram em espaços privilegiados ao desenvolvimento linguístico, pessoal, social e acadêmico das crianças surdas. Vale ressaltar que utilizaremos, com mesmo significado, as denominações "sala LIBRAS língua de instrução", sala "língua de instrução Libras" e sala multisseriada - Língua de Instrução Libras.
}

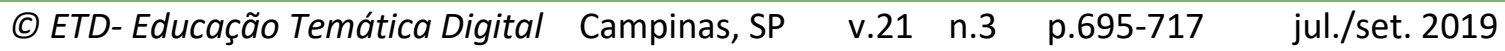


surdos em uma mesma sala, contraria o que prevê a Política Nacional de Educação Especial, mas tem mostrado resultados interessantes os quais serão aqui partilhados (algumas análises).

Desta maneira, o Programa tem se configurado como uma educação outra aos alunos surdos. Enquanto a Política ${ }^{8}$ insiste em ver o surdo pelo viés da deficiência e considera apenas o que lhe falta: a audição; o Programa, por sua vez, considera a diferença linguística do surdo e busca assegurar que sua singularidade seja respeitada.

Em contrapartida, as implantações e produções do Programa Inclusivo Bilíngue nos diversos municípios, serão aqui entendidas como ações resistivas ${ }^{9}$, pois por olhar a surdez pela sua relação de diferença corporal, cultural e linguística, propõe uma educação inclusiva outra às crianças surdas. Filiam-se a este modo de pensar a surdez, fazeres que agenciem a língua de sinais e as relações culturais do surdo (LOPES, 2011; MARTINS, 2013, 2016). Tais aportes invadem a escola criando programas e políticas públicas, e com elas, as resistências aos modelos engessados. Por esse motivo a pesquisa apresentada se propôs olhar práticas de docentes bilíngues em salas com instrução em Libras ofertadas nos moldes destes programas apresentados.

\section{PROCEDIMENTO METOdOlógICO PARA A REALIZAÇÃo DA PRESENTE PESQUISA}

Para a coleta de dados e análise das práticas docentes com alunos surdos foram observadas duas salas multisseriadas em escolas-polo inclusivas bilíngues no interior do estado de são Paulo. Foram realizados quatro encontros em cada unidade escolar. No primeiro encontro, além da observação da aula, foi realizada uma entrevista com as participantes. Foram utilizados os instrumentos de: a) observação da prática pedagógica das professoras participantes e registros em diário de campo; b) entrevistas com as professoras participantes deste estudo. Tais instrumentos foram escolhidos por considerar que "a observação apresenta como principal vantagem, em relação a outras técnicas, a de que os fatos são percebidos diretamente, sem qualquer intermediação" (GIL, 2008, p.100). E a entrevista, por ser "muito eficiente na obtenção de dados em profundidade acerca do comportamento humano" (GIL, 2008, p. 110).

As observações focaram aspectos da atuação das professoras bilíngues, como: metodologia adotada durante as aulas; estratégias adotadas para o trabalho com a Língua de Sinais e com a Língua Portuguesa, especificamente; espaços ocupados por essas línguas na

\footnotetext{
${ }^{8} \mathrm{O}$ termo refere-se à Política Nacional de Educação Especial (PNEE) e será utilizado em itálico para enfatizar propositalmente as oposições entre Política versus Programa (Programa Educacional Inclusivo Bilíngue).

${ }^{9}$ As discussões sobre as práticas cotidianas resistivas que se dão no interior das salas multisseriadas língua de instrução Libras serão adensadas a seguir, alinhadas ao conceito de resistência cunhado por Michel Foucault, conforme apontado na introdução deste artigo.
}

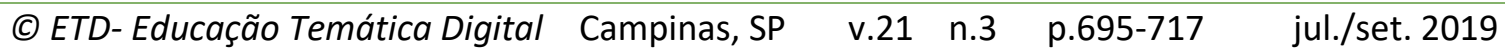


sala de aula; formas e instrumentos de avaliação do processo de ensino e aprendizagem. Os registros realizados a partir das observações subsidiaram a elaboração de novas questões às participantes e tais questionamentos foram realizados ao longo das observações. Aqui neste artigo, por questões de espaço restrito para a discussão, faremos uso de uma única cena como elemento produtor das nossas reflexões alinhavando-a ao referencial teórico adotado.

Aliar os dois instrumentos de coleta de dados forneceu ao estudo maior confiabilidade, permitindo uma análise mais detalhada dos dados obtidos. Essa é a característica da pesquisa com o cotidiano: a diversidade e relação entre os instrumentos utilizados durante a coleta de dados que permitem ao pesquisador "mergulhar" no contexto estudado, trazendo maior propriedade para o momento da análise. Como afirma Ferraço (2007, p.81, grifos do autor), "eu não penso "sobre" o cotidiano, eu penso "com" o cotidiano".

O cotidiano exige dos pesquisadores em educação outras possibilidades teóricometodológicas, diferentes daquelas herdadas da modernidade, para superar o aprisionamento do cotidiano em categorias prévias e assegurar a impossibilidade de usarmos o singular para tratar da diversidade que se manifesta na vida (FERRAÇO, 2007, p. 73).

Portanto, os dados obtidos foram analisados de maneira qualitativa, à luz do referencial teórico adotado nesta pesquisa, fundamentados por conceitos cunhados por Michel Foucault, Gilles Deleuze e outros autores alinhados às Filosofias da Diferença. É importante salientar que as análises foram realizadas como complementares a teoria filosófica apresentada. A cena ilustrada a seguir possibilitou uma descrição de acontecimentos do cotidiano escolar, permitindo a articulação aos aspectos teóricos elucidados no decorrer deste texto.

\section{SALA MULTISSERIADA E A HETROTOPIA: ANÁLISES DAS RESISTÊNCIAS NAS AÇÕES DOCENTES EM UMA CENA ESCOLAR}

A emergência do cotidiano na escola, o acontecimento-cotidiano, é tudo aquilo que escapa do nosso planejamento, seja como professores, como gestores do processo educacional, como funcionários da instituição escolar, seja como pais. E a questão decisiva é: de que modo reagimos aos acontecimentos cotidianos? A resposta é de fundamental importância, pois esses acontecimentos são potencialmente situações formativas (GALLO, 2007, p. 24).

Para as análises, portanto, escolhemos uma cena que ilustra apontamentos da importância das salas multisseriadas e as ações menores, de resistência neste espaço considerado como sendo heterotópico. A reflexão foi estabelecida a partir da problematização/questionamento lançada (o) acima por Gallo (2007, p.24): "De que modo reagimos aos acontecimentos cotidianos?". O encontro com as filosofias da diferença promoveu outro olhar para aquilo que é inusitado e os efeitos corpóreos diante dos acontecimentos - algo que deve ser trabalhado com os docentes sem formatar as respostas aos acontecimentos. Digamos que a reação frente aos acontecimentos cotidianos são focos

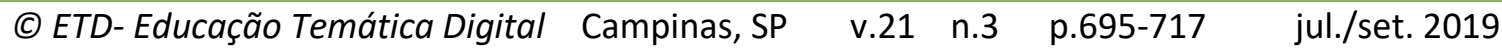


de grande relevância para este estudo. Saber que os encontros entre alunos e docentes podem produzir feixes distintos ao planejamento primeiro do docente é importante, além de observar as ações-respostas dadas a essas situações que não foram previamente orquestradas, planejadas ou previstas. Esse aspecto é o que diferenciará o professor-profeta do professor-militante, justamente pela forma como ele encara e reage a esses acontecimentos não programados.

O professor crítico, o professor consciente das suas relações sociais, de seu papel político agiria como um professor profeta [...]. O professor profeta é alguém que anuncia as possibilidades, alguém que mostra um mundo novo. Por outro lado, podemos pensar no professor militante [...]. Mesmo em situações em que os alunos não são nem um pouco miseráveis do ponto de vista econômico, certamente eles experimentam uma série de misérias outras. O professor militante seria aquele que, vivendo com os alunos o nível de miséria que esses alunos vivem, poderia, de dentro desse nível de miséria, de dentro dessas possibilidades, buscar construir coletivamente. Essa é a chave da ação do militante. Sempre uma construção coletiva (GALLO, 2002, pp. 170-171).

No percurso de busca por essa militância, destacamos a importância de ida às escolas pela possibilidade ímpar de aprender com as observações realizadas e observar a ação coletiva das docentes bilíngues ao enfrentar o novo na parceria constante aos estudantes surdos, em suas singularidades - dada as salas multisseriadas de surdos com dois ciclos em funcionamento. Durante a coleta de dados, as leituras realizadas até então, nos faziam total sentido. Pois, foi possível perceber a emergência de acontecimentos, que eram evidentes: não tinham sido propostos pelas professoras, não haviam sido planejados, mas traziam efeitos corpóreos aos alunos de modo significativo. Nestes eventos, observar como cada uma encontrava, no acontecimento, uma oportunidade de atingir o aluno e de formá-lo, ou seja, de caminhar com ele a partir de suas inquietações, pareceu-nos assertivo.

Não afirmamos que os planejamentos realizados a todo instante durante o ano letivo: plano anual de ensino, planejamento bimestral e semanal, planejamento da rotina diária e de sequências didáticas, bem como outros instrumentos com a mesma finalidade, devam ser extintos. Porém, percebemos que para além de tudo que nós professores pensamos e determinamos que deva ser feito, é possível, ou melhor, é imprescindível dar voz ao aluno, ou ainda, permitir sua aparição na construção coletiva do ensino. Possibilitar a escuta de seu percurso e de suas aprendizagens no processo. Apontar a necessidade da voz parece estranho tratando-se de alunos surdos, mas o termo foi aqui usado no sentido de dar espaço à curiosidade do aluno; às suas dúvidas e anseios; aos eventos de noticiários; enfim, as situações que muitas vezes ignoramos por estarmos demasiadamente preocupados em cumprir tarefas burocráticas que nos sãos exigidas, ou com o conteúdo sistematizado, sem atentar ao currículo oculto, ou aos saberes locais, os saberes dos alunos. É desafiador, porém, urgente que tracemos um novo percurso na docência, rompendo com determinismos e postura cristalizada de conceber o professor como o detentor do saber; o produtor de

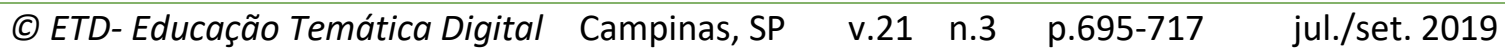


verdades inquestionáveis. Esses aspectos foram base para as análises, embasados em conceitos e pressupostos das filosofias da diferença. Neste sentido, alinhados a essa discussão, segue a cena, "A vinda do biólogo", como exemplo de atuações pedagógicas outras: ações inventivas e heterotópicas (FOUCAULT, 2013) uma vez que a partir da curiosidade de um dos alunos surdos, acerca do que estava sendo trabalhado em sala de aula, a educadora bilíngue operacionaliza formas de dialogar com o desejo do aluno, fazendo da sala de aula espaço aberto às novidades e problematizações trazidas pelos participantes. Destacamos que este evento foi retirado dos dados de uma pesquisa de mestrado na Universidade Federal de São Carlos, realizada pela primeira pesquisadora e orientada pela segunda. Por se tratar de uma sala multisseriada bilíngue, tendo alunos do Ciclo I e Ciclo II, a professora fazia adaptações do conteúdo escolar o tempo todo, de modo a atingir/adequar aos diferentes estudantes surdos (em anos variados). Os alunos se dispunham diariamente em semicírculo favorecendo a troca visual e a interação na língua de sinais. A configuração física da sala já permitia observar mudanças na dinâmica comum proposta pela organização escolar - na maioria das vezes mantendo as carteiras enfileiradas. O excerto abaixo tratará da curiosidade do aluno $\mathrm{M}$, do $5^{\circ}$ ano, que faz uma observação à professora a partir de algo que ocorre no intervalo. A educadora bilíngue acolhe a inquietação, fazendo dela um acontecimento de ensino.

\section{Excerto 1 - A vinda do biólogo.}

(Todos os alunos encontram-se sentados em semicírculo realizando atividades de matemática relacionadas ao tema medidas de comprimento e instrumentos de medida. As atividades são diferentes, com nível de adequação a cada ano escolar. Só um aluno do ciclo I compareceu neste dia. Ele frequenta o 1a ano e estava realizando a ilustração de uma casa. A professora lhe explicou a atividade dizendo que deveria se lembrar dos cômodos que compõem uma casa, já estudados outro dia e sua tarefa era desenhar uma casa com o maior número de detalhes. Os alunos do ciclo Il estavam com tablets e desenhavam uma planta baixa utilizando um programa específico para esse fim, chamado Planner $5 D$ ).Dora ${ }^{10}$ \{Port\}: J. após o intervalo vamos ter que mudar o tema da aula. Eles ainda não concluíram as atividades, isso é ruim, mas era o dia que o rapaz podia vir. Ah, deixa eu contextualizar para você entender: nós estávamos trabalhando o corpo humano e bem na época que estávamos estudando o sistema circulatório, o M (aluno do 5o ano) se machucou e chegou aqui dizendo que eu era mentirosa porque ele não conseguia ver em seu machucado tudo o que eu disse que tinha no sangue: glóbulos vermelhos, glóbulos brancos, plaquetas.... Eu retomei que não dava mesmo para ver sem um microscópio. Acredita que o $\mathrm{M}$ sugeriu então para pedirmos ao prefeito que comprasse um para ficar aqui na escola? Na ocasião eu até pensei em fazer um projeto onde faríamos uma carta pedindo, mas o contexto político aqui da cidade especialmente em relação à nossa sala está tão complicado que achei melhor não..., mas me lembrei desse biólogo amigo do meu marido que trabalha em uma das escolas mais caras aqui da cidade. Conversei com ele e ele topou fazer algo com as crianças. Na verdade, a proposta dele foi até de levarmos os alunos até sua escola, porque tem toda estrutura, laboratórios..., mas não estamos conseguindo transporte para atividades extra-classe, a prefeitura não está liberando. Expliquei isso a ele e topou vir aqui com sua assistente. Ele vai trazer vários instrumentos. Acho que vai ser bem legal! Daqui a pouco a $\mathrm{G}$ (professora que atua com Dora na sala) vai buscá-lo. Ela tem uma "janela" e vai dar certinho. Depois eu a ajudo com o combustível, porque onde ela vai é um pouco longe, sabe....

${ }^{10}$ Os nomes trazidos neste artigo são fictícios.

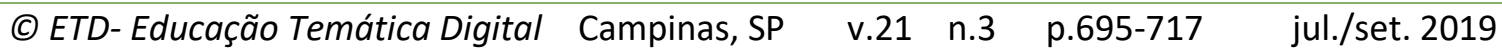


(A professora $G$ havia comentado comigo no início da aula, que conversaram com a direção pedindo autorização para sair da escola e ir buscar o biólogo. Ela utilizou uma aula sua de "janela" (momento livre para planejamento pedagógico) e seu automóvel particular para isso. O biólogo e sua assistente chegaram trazendo muitos materiais: microscópios; lâminas; lentes de aumento; alguns alimentos que utilizariam nos experimentos; dentre tantos outros. À medida que organizavam os materiais sobre a mesa, posicionada à frente da sala, os alunos estavam focados, demonstrando muito interesse com a aula que se iniciaria. A professora Dora apresentou-os (biólogo e assistente) à turma. Durante toda a explicação do biólogo, as professoras bilíngues revezavam na interpretação de sua fala à Língua de Sinais. A cada explicação, quando Dora percebia que o conteúdo estava denso demais aos alunos menores; ela pedia licença ao professor biólogo e fazia contextualizações; complementava a explicação com desenhos na lousa, buscas de imagens na internet que era projetada a todos da sala e exemplos mais acessíveis à compreensão das crianças. Foi uma manhã bastante produtiva. Os alunos participaram atentamente e ativamente da aula).

M (aluno do 5o ano) \{LIBRAS\}: Mas e o sangue? Eu quero muito ver o que tem no sangue.

Biólogo \{Port\}: Vou te mostrar imagens ampliadas que trouxe para você ver, pois não consegui trazer as lâminas com sangue hoje. Mas acho que você vai compreender.

( $M$ manteve-se muito atento, realizando inclusive algumas perguntas ao biólogo, demonstrando ter compreendido).

Dora \{LIBRAS\}: Já está na hora de finalizarmos a nossa aula. Vocês gostaram? Eu amei! (Neste momento, voltase ao biólogo e diz emocionada) \{Port\}: Obrigada Elton (nome fictício do biólogo)! Fiquei muito feliz com sua vinda! Obrigada mesmo! Foi ótimo!

Dora (ainda emocionada diz aos alunos) \{LIBRAS\}: O Elton veio voluntariamente e ainda trouxe tudo isso. Estou muito feliz!

(aluno do 5o ano) \{LIBRAS\}: o que é esse sinal? (faz o sinal de voluntário utilizado pela professora).

Dora \{LIBRAS\}: Voluntário significa de graça, não cobrou nada. Eu não tenho dinheiro para pagar o Elton. Ele veio e eu e a professora $\mathrm{G}$ não pagamos nada a ele. Ele veio sem ganhar nada e trouxe todas as coisas dele. Coisas próprias dele. Que legal! Quis ajudar! Ele tem bom coração, é uma pessoa boa! Entendeu K?

(K indica positivamente com a cabeça. Os alunos organizam seus materiais e se despedem das professoras e de mim - pesquisadora).

O excerto acima nos permite destacar vários aspectos e por meio deles é possível traçar algumas reflexões. Inicialmente, a maneira como um acontecimento cotidiano pode possibilitar situações formativas aos alunos e mesmo às professoras, como foi o que ocorreu neste caso. Se quando o aluno $\mathrm{M}$ questionou a professora Dora sobre a composição sanguínea a mesma tivesse lhe dado uma resposta autoritária, impondo-Ihe seu ensino, sem abertura ao diálogo e respeito às inquietações do aluno, a aula tão rica de aprendizado e experiências não teria ocorrido. Se a questão se tornou problema para o aluno, a professora o refaz, numa ação militante, tal qual ao conceito cunhado por Gallo (2002), como sendo "aquele que, vivendo com os alunos o nível de miséria que esses alunos vivem, poderia, de dentro desse nível de miséria, de dentro dessas possibilidades, buscar construir coletivamente". Deste modo, ainda que o planejamento faça parte da dinâmica do professor, o percurso e interesse dos alunos produzem outras formas de condução da proposta docente e ela não titubeia em pensar formas de ampliar as perguntas do aluno: buscando maneiras de apresentar algumas respostas para além das oferecidas nos livros didáticos, experiências práticas externas à

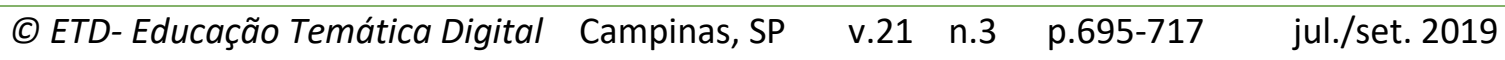


escola - na vinda do biólogo. Apontamos tal fazer como ação de resistência, uma vez que pela escola não haveria como levar os alunos ao laboratório, tampouco, pagar a vinda do especialista e ainda assim o "não" de modo algum paralisou as ações na direção de outros caminhos para fazer a aula acontecer. Militantemente, a potência do encontro à inquietação do aluno surdo, promove na docente, formas outras (novas vias) de sanar as impossibilidades. Esse movimento flexível que, por vezes, modifica a própria programação do professor é efeito dessa proposta escolar que torna o cotidiano como espaço de aprendizagem e formação.

\footnotetext{
Para os profissionais da educação, a lição das ideias de Foucault é a necessidade de estarem atentos quando, na prática profissional, induzem, incitam, desviam, facilitam ou dificultam, produzem, ampliam ou limitam qualquer conteúdo trabalhado. Nessas práticas, o exercício do poder modela corpos e mentes; e nessas relações de poder, estabelecem-se "verdades" e constituem-se sujeitos - crianças, adolescentes, professores/as, gestores/as [...] (CAMARGO, 2007, p. 59, grifo do autor).
}

A perspectiva criativa se dá no fluxo do encontro com o inesperado no processo do aprender do aluno que se dá fora da sala de aula: "[...] nunca aprendemos como, mas sempre com alguém" (GALLO, 2012, p.4; destaque do autor). Esse encontro não programado ocorre pelas problematizações cotidianas traçadas como lutas a serem vencidas: o aluno $\mathrm{M}$ enfrenta a docente, no saber que Ihe foi ensinado por ela. Imediatamente a docente faz disso disparador para novos encontros num espaço de ampliação do diálogo - ação de resistência efeito de uma educação menor.

\section{Uma educação menor é trincheira (ou, para dizer como Deleuze e Guattari, toca, resultado de um devir-animal), espaço de resistência, não um programa. Colocar-se à deriva, como barcos em águas desconhecidas. $\mathrm{E}$, na repetição destas experiências, criar o diferente [...] justapor, no mesmo espaço, a experiência, a aventura, a política como emergência do inusitado nas relações (GALLO, 2016a, p.43, grifos do autor).}

Ainda que a escola seja modelada como espaço formativo e de consolidação de verdades, as ações dos sujeitos nela produzem e ressoam distintas relações e saberes. Assim, o olhar atento da professora Dora à dúvida e questionamento de seu aluno, incitou, facilitou e possibilitou uma vivência diferenciada, mais significativa e contextualizada e isso certamente contribuiu com a aprendizagem dele e dos demais alunos. Para além do programa proposto pelo livro didático ou de um planejamento que é elaborado para que uma rede toda de ensino o siga, neste caso, a aula contemplou as demandas de um aluno, mas não somente, possibilitou inclusive ter acesso a muitos outros conteúdos que foram apresentados naquela manhã pelo biólogo. Sem preocupações com o conteúdo que não deveria ser apresentado ainda naquele momento; sem subestimar a capacidade dos alunos; no entanto; aproveitando as possibilidades formativas que um acontecimento pode gerar. Sem dúvida, é preciso adequar a linguagem e utilizar diferentes estratégias para que o conteúdo se torne acessível a todos os alunos e contemple todas as faixas etárias, mas um mesmo conteúdo pode ser apresentado de diversas maneiras, atingindo alunos maiores e menores. Destacamos que o

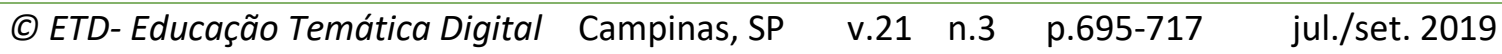


processo só ocorreu pela interação parceira por meio de uma língua comum entre alunos e docente bilíngue, a Libras (LODI; LACERDA, 2009). A heterotopia como conceito aparece na medida em que a sala multisseriada fisicamente promove outro espaço e novas práticas à perspectiva inclusiva: promove o ensino para alunos em anos diferentes; usa a Libras como língua de instrução e não a língua portuguesa como padroniza o currículo comum; agrega experiências práticas que rompem com as normativas de ensino.

O segundo aspecto que podemos discutir do excerto é a postura da professora que não se limitou, fazendo todos os esforços necessários para que uma aula diferenciada acontecesse. Ela poderia ter desistido desde o primeiro momento, justificando aos alunos que infelizmente a escola é desprovida de recursos, portanto, caberia a eles acreditarem nas explicações em sala de aula sobre a composição sanguínea, sem possibilidade de questionamentos. Porém, ela não parou em suas impotências, atuando, como descrito anteriormente, como professora-militante, na criação de linhas de fuga a fim de que seus alunos tivessem uma aula mais próxima aos seus anseios.

A educação construiu-se como "aparelho de Estado", para atender às prerrogativas do Estado para com a educação. Mas há também em nossas escolas "máquinas de guerra" que não se deixam capturar por este aparelho de Estado, criando linhas de fuga e possibilidades outras para os processos educativos (GALLO, 2016b, p. 998, aspas do autor).

Como professora-militante, fez uso da "máquina de guerra" como potência de perfuração do mesmo, rumo à diferença educacional. Colocou-se resistente ao sistema de ensino que é, por vezes, precário em recursos, fazendo de nossas escolas públicas espaços desprovidos de materiais diversificados. A resistência e busca de práticas experienciadas pelo fazer empírico serviu como estratégia que favoreceu o interesse coletivo: para além do aluno $M$, os demais alunos, mesmo em anos diferenciados puderam aproveitar da presença do participante como um espaço de encontro com o conteúdo apresentado por outras rotas. Foi necessário abrir mão do horário de planejamento pessoal, dispondo inclusive de recursos próprios para que fosse possível a realização da aula. Mobilizada com o caminhar dos alunos e o desejo inquieto deles a docente bilíngue colocou-se na guerrilha de outros espaços que potencializassem o aprender. Pensando no conceito de educação menor que já discutimos anteriormente, esse movimento da professora Dora parece ser um bom exemplo. Diante de um discurso majoritário da impossibilidade, da inexistência de recursos, da conformidade, ela resistiu e criou uma alternativa possível: a criação é a mola propulsora da menoridade, ou da ação menor na educação (GALLO, 2016a). Para além dessa cena, outros elementos do cotidiano escolar, nessa sala de aula multisseriada, como a produção de materiais específicos na Libras, atividades coletivas produzidas para alunos com interesses e anos distintos, adequação de conteúdo para alunos em processo de aquisição da língua de sinais, favorecem a afirmação da potência criativa/inventiva deste espaço para alunos surdos. Seus atos silenciosos, solitários e de resistência, entre a educadora Dora e seus alunos, possibilitaram 
uma rica experiência de formação, ou de confabulação às crianças. Importante destacar que embora a participante deste estudo (desta sala) seja apenas a professora Dora, ressaltamos as ações da outra professora (da outra escola polo-bilíngue observada), por compreender que muitas ações de enfrentamento à normativa de um ensino baseado na lógica produzida para alunos que ouvem, são comuns entre as duas. Tal fator, o da riqueza da inventividade trazida nestas salas multisseriadas favoreceram para a emergência de acontecimentos como esse descrito acima, no qual a educadora, oferece as mais variadas formas de incentivo ao aprendizado de alunos surdos. Tais ações merecem destaque considerando o atraso na aquisição de linguagem (aquisição da língua de sinais apenas na escola) dos alunos surdos, os quais, por vezes, trazem questões diferentes do previsto na formação comum de um pedagogo. Já que se observa o não apontamento de metodologias de ensinos, nas formações gerais, voltadas para alunos que não tem o português como primeira língua.

\title{
6 CONSIDERAÇÕES FINAIS E ABERTURAS DE NOVAS REFLEXÕES
}

\author{
Se aceitarmos o desafio de Foucault, teremos uma Educação para muito além da \\ disciplinarização e da técnica (...). Uma educação voltada para o cuidado de si \\ mesmo e do outro, possibilitando novas formas de produção de si e de relações com \\ os outros (GALLO, 2004, p. 95).
}

Uma prática pedagógica que rompe com a disciplinarização dos corpos e importase com as produções de si e com sua relação com os outros é por si uma prática de resistência e produz uma educação menor, ou uma educação outra. Neste estudo nos propomos olhar para as salas multisseriadas "língua de instrução Libras" como possíveis espaços heterotópicos, carregados de linhas de fuga, resistências e criação. Através dos dados coletados e aqui apresentados por uma cena, podemos inferir que tais salas se caracterizam como espaços de produção ampla de resistências (que considera a singularidade do aluno) à proposta de educação inclusiva que concebe a escola como um lugar para todos, mas nessa tentativa de homogeneizar só exclui, ou produz, por vezes, o esmagamento da diferença. Portanto, essa configuração de sala multisseriada, para nós, é uma oferta de educação menor (educação pela criação da e na Libras) aos surdos. Uma educação que considera a diferença e a valoriza, sem preocupar-se com os rótulos de ilha, de gueto, de modelo que segrega - pois ela potencializa a aparição e a escuta dos surdos.

Desta forma, as salas multisseriadas, para alguns municípios, contrariam a proposta da Política inclusiva voltada à Educação Especial quando agrupa todos os surdos em um mesmo espaço. Todavia, a pesquisa mostrou que essa configuração permitiu uma inclusão aparentemente mais possível e mais ética desses alunos, isso porque, como pudemos ver ao longo da investigação, os alunos surdos que frequentam as salas multisseriadas além de maior facilitação para o desenvolvimento linguístico e constituição de sua subjetividade surda, não ficam à margem do processo educativo, como vemos ocorrer em muitas experiências 
educacionais que fazem a inclusão escolar sem a valorização linguística e suas especificidades culturais.

Nas salas multisseriadas, propostas nestes projetos investigados de educação inclusiva bilíngue, os alunos têm oportunidade de acessar os conteúdos comuns por meio da sua língua, de forma mais natural e não superficialmente, como nos casos de surdos que precisam realizar leitura labial, dependentes da ação do professor em manter-se posicionado à sua frente, podendo nem sempre conseguir fazer uma boa leitura das explicações por essa via. Neste espaço o aluno tem ainda, a liberdade de realizar trocas na e pela língua com seus amigos surdos e com seu professor. Ele não está isolado, como ocorre na maioria dos casos, onde apenas um surdo é incluído em salas com ouvintes. Nestes contextos de inclusãoexcludente, o surdo muitas vezes não tem amigos e quando tem a sorte de ser acompanhado por um intérprete, é só com ele que consegue realizar trocas. Imagina frequentar um espaço diariamente onde não se possa conversar, bater papo, fazer amigos.... Isso, muitas vezes, ocorre em nossas escolas brasileiras que se dizem inclusivas e para todos: uma exclusão cotidiana linguisticamente para os surdos.

No entanto, na observação realizada, as salas multisseriadas valorizam a diferença surda e em todo o processo são consideradas suas singularidades e por isso, são utilizadas estratégias e recursos adequados de modo visual. A esse ponto, devemos destacar a atuação das professoras bilíngues atuantes nestas salas. Essa foi outra inquietação que norteou essa pesquisa e agora podemos retomá-la. Pretendíamos analisar as práticas das docentes e finalizamos este estudo certas de que cumprimos essa tarefa. As professoras se mostraram resistentes ao propor um trabalho que rompe com a multidisciplinaridade numa lógica de segmentação disciplinar rumo ao transdisciplinar à ação do acontecimento via desejo de seus parceiros-estudantes. Ao darem espaço de aparição aos seus alunos, quando respeitam seus questionamentos e curiosidades, mesmo sabendo que ao adotarem tal postura, o planejamento a priori delineado é alterado, a proposta se mostra inovadora pelo compromisso com o todo e com o uno: com cada um que figura o espaço múltiplo. Promovem uma educação menor quando agem com micro-ações que oferecem uma educação outra a seus alunos, mesmo mergulhadas em ambientes, por vezes, desmotivadores e carentes de recursos.

Desta maneira, consideramos neste momento histórico, essas salas multisseriadas para surdos como um espaço heterotópico e que tem respeitado a diferença surda. Foi possível perceber o quanto a configuração da multisseriação pensada a uma educação bilíngue para surdos é novidade nos estudos da área e ainda desconhecida por muitos, que a associam frequentemente às escolas rurais, de modo pejorativo, sem valorizar o que de mais rico estes modelos tem trazido: o da anunciação de perspectiva que trazem o ensino para o múltiplo e para a diferença: de ser, de conhecimento, de idade, de nível de aquisição e

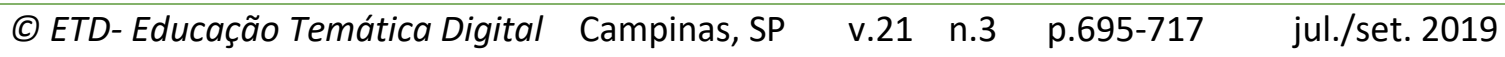


apropriação da língua entre os alunos observados. O desafio e a beleza da pesquisa, está em mostrar a potência da diferença na relação e condução docente em salas como essa em que o mesmo, o homogêneo não pode se dar como regra.

\section{REFERÊNCIAS}

BRASIL. Lei no $\mathbf{1 0 . 4 3 6}$ de 24 de abril de 2002. Brasília, DF: Presidência da República, Casa Civil, Subchefia para Assuntos Jurídicos. Disponível em: http://www.presidencia.gov.br/CCIVIL/LEIS/2002/L10436.htm . Acesso em: 15/04/2017.

BRASIL. Decreto no 5626, de 22 de dezembro de 2005. Brasília, DF: Presidência da República, Casa Civil, Subchefia para Assuntos Jurídicos. Disponível em: http://www.presidencia.gov.br/ccivil/ Ato2004-2006/2005/Decreto/D5626.htm . Acesso em: 21/04/2016.

CARVALHO, A. F. de. Da sujeição as experiências de construção de si na função-educador: uma leitura foucaultiana. 2008. 204p. Tese (doutorado) - Universidade Estadual de Campinas, Faculdade de Educação, Campinas, SP, 2008.

CARVALHO, A. F de ; MARTINS, V. R. O. Anunciação e insurreição da diferença surda: contraações na biopolítica da educação bilíngue. In: Childhood \& Philosophy, Rio de Janeiro, v. 12, n. 24, pp. 391-415, mai./ago. 2016.

CAMARGO, A.M.F. de. Sala de aula e cotidiano escolar. In: CAMARGO, A. M. F. de; MARIGUELA, M (Org.). Cotidiano escolar: emergência e invenção. Piracicaba: Jacintha, 2007.

DELEUZE, G.; GUATTARI, F. Kafka - por uma literatura menor. Rio de Janeiro: Imago, 1977.

DELEUZE, G.; GUATTARI, F. O que é a filosofia? Rio de Janeiro: Ed. 34, 1992.

FERRAÇO, C. E. Pesquisa com o cotidiano. Revista Educação e Sociedade, Campinas: v. 28, n. 98, p. 73-95, jan./abr. 2007.

FOUCAULT, M. O governo de si e dos outros. Curso no Collège de France (1982-1983). São Paulo: Martins Fontes, 2010.

FOUCAULT, Michel. O corpo utópico, as heterotopias. São Paulo: n.1 Edições, 2013.

FOUCAULT, M. Microfísica do poder. Rio de Janeiro: Paz e Terra, 2014.

GALLO, S. Em torno de uma educação menor. Revista Educação e Realidade, p. 169-178, jul./dez. 2002.

GALLO, S. Repensar a educação: Foucault. Revista Educação e Realidade, p. 79-97. jan./jun., 2004.

GALLO, S. Acontecimento e resistência: educação menor no cotidiano da escola. In: CAMARGO, A. M. F. de; MARIGUELA, M. (Org.). Cotidiano escolar: emergência e invenção. Piracicaba: Jacintha, 2007.

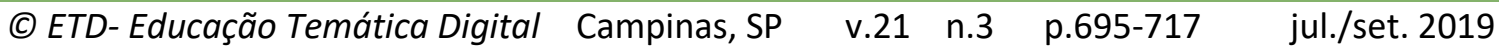


GALLO, S. Em torno de uma educação menor: variáveis e variações. In: BRITO, M. R. de; GALLO, S. Filosofias da diferença e educação. São Paulo: Livraria da Física, 2016a.

GALLO, S. Possibilidades e linhas de fuga: a invenção de escolas outras no dia a dia. Revista Eventos Pedagógicos. Número Regular: Formação de Professores e Desafios da Escola no Século XXI Sinop, v. 7, n. 2 (19. ed.), p. 994-1003, jun./jul. 2016b.

GALLO, S.; ASPIS, R. L. Foucault e a educação. Coleção Filósofos e Educação (DVD). São Paulo: Paulus, 2011.

GIL, A.C. Métodos e técnicas de pesquisa social. São Paulo: Editora Atlas, 2008.

LACERDA, C. B. F.; SANTOS, L. F.; MARTINS, V. R. O. (Org.). Escola e diferença: caminhos para a educação bilíngue de surdos. São Carlos: EDUFSCar, 2016.

LACERDA, C.B.F de; SANTOS, L.F.dos; LODI, A.C.B.; GURGEL, T.M.A. Educação inclusiva bilíngue para alunos surdos: pesquisa e ação em uma rede pública de ensino. In: LACERDA, C.B.F. de; SANTOS, L.F.dos; MARTINS, V.R.O. (Org.). Escola e diferença: caminhos para educação bilíngue de surdos. São Carlos: EdUFSCar, 2016.

LODI, A. C. B; LACERDA, C.B. F. (Org.). Uma escola, duas línguas: letramento em língua portuguesa e língua de sinais nas etapas iniciais de escolarização. Porto Alegre: Mediação, 2009.

LODI, A.C.B. Educação bilíngue para surdos e inclusão segundo a Política Nacional de Educação Especial e o Decreto no 5.626/05. Educação e Pesquisa (USP. Impresso), v. 39, p. 49-63, 2013.

LOPES, M.C. Surdez e educação. Belo Horizonte: Autêntica, 2011.

LUZ, R.D. Cenas surdas: os surdos terão lugar no coração do mundo? São Paulo: Parábola, 2013.

MAHER, T.M. Do casulo ao movimento: a suspensão das certezas na educação bilíngue e intercultural. In: CAVALCANTI, M.C; BORTONI-RICARDO, S.M. (Org.). Transculturalidade, linguagem e educação. Campinas: Mercado de Letras, 2007.

MARTINS, V. R.O. Posição-mestre: desdobramentos foucaultianos sobre a relação de ensino do intérprete de língua de sinais educacional. Tese (Doutorado em Educação) - Universidade Estadual de Campinas, Campinas, SP, 2013.

MARTINS, V.R.O. Educação de surdos e proposta bilíngue: ativação de novos saberes sob a ótica da filosofia da diferença. In: Educação \& Realidade. Porto Alegre, v. 41, n. 3, 2016.

MURAD, M. F. G. O sujeito em Foucault. Rio de Janeiro, 2010. Disponível em: http://www.spid.com.br/pdfs/2010-2/Atividades-Jornadas-Interna-2010.1-O-SUJEITO-EMFOUCAULT-Maria-Fernanda-Guita-Muraddoc.pdf . Acesso em: 29/10/2017. 
SOUZA, R.M. de. Educação de surdos e questões de norma. In: LODI, A.C.B. et.al. Letramento e minorias. Porto Alegre: Mediação, 2010.

SILVA, V. Educação de surdos: uma releitura da primeira escola Pública para surdos em Paris e do Congresso de Milão em 1880 In: QUADROS, R. M. de (Org.). Estudos surdos I. Petrópólis, RJ: Arara Azul, 2006.

VEIGA-NETO, A.; SARAIVA, K. Educar como arte de governar. Currículo sem fronteiras, v.11, n.1, p.5-13, jan./jun. 2011.

Revisão gramatical realizada por:

Mariana Peres Morais.

E-mail: marianaperesm@gmail.com. 